\title{
Risk factors for developing anorectal dysfunction after anterior resection
}

\author{
Kevin Afshari ${ }^{1}$ (I) Kenneth Smedh ${ }^{1} \cdot$ Philippe Wagner $^{2} \cdot$ Abbas Chabok $^{1} \cdot$ Maziar Nikberg $^{1}$
}

Accepted: 26 August 2021 / Published online: 2 September 2021

(c) The Author(s) 2021

\begin{abstract}
Background Anterior resection (AR) may result in defecatory dysfunction and the cause is multifactorial. The aim was to explore if dysfunction could be related to the part of the colon used for anastomosis (sigmoid or descending) and to identify other possible risk factors for bowel dysfunction after AR.

Methods This is a retrospective study based on prospectively registered data from a regional registry at the surgical department in Västmanland 1996-2019. Bowel function was registered at 1 year after AR or after stoma reversal. In total, 470 stage I-III rectal cancer patients had AR whereof 412 were included in this study.

Results Clustering was seen in $57 \%$, incontinence $29 \%$, urgency $22 \%$, and evacuatory dysfunction $16 \%$. The part of the colon used for anastomosis, level of vascular tie, and gender were not significantly associated with defecatory dysfunction. The higher the anastomotic level, the lower the risk of incontinence (OR 0.75 ; CI $0.63-0.90 ; p<0.001)$ and clustering (OR 0.78 ; CI $0.67-0.90 ; p<0.001)$. Compared with patients without a loop-ileostomy, an increased risk of clustering (OR 1.89; $1.08-3.31 ; p=0.03$ ), incontinence (OR 2.48; 1.29-4.77; $p<0.01$ ), and urgency (OR 4.61; CI 2.02-10.60; $p<0.001$ ) was seen after loop-ileostomy closure. Preoperative radiotherapy had a negative impact on continence and clustering seen mainly in the unadjusted analysis.

Conclusion The part of the colon used for anastomosis was not a significantly associated functional outcome after anterior resection. Low anastomotic level and having had a diverting ileostomy were independent risk factors associated with negative functional outcomes.
\end{abstract}

Keywords Anorectal dysfunction - Anterior resection syndrome $\cdot$ Functional bowel disturbance $\cdot$ Anterior resection . Bowel disturbance $\cdot$ Functional outcome $\cdot$ Bowel dysfunction

\section{Introduction}

The gold standard for the treatment of adenocarcinoma in the rectum has been the sphincter-sparing anterior resection (AR) [1]. However, there are long-term side effects of which defecatory dysfunction including incontinence for feces and flatus, urgency, diarrhea, frequency, and clustering are the most common. This combination of symptoms is recognized as low anterior resection syndrome (LARS)

Kevin Afshari

kevin.afshari@regionvastmanland.se

1 Colorectal Unit, Department of Surgery and Centre for Clinical Research of Uppsala University, Västmanland's Hospital Västerås, 72189 Västerås, Sweden

2 Centre for Clinical Research, Uppsala University, Hospital of Vastmanland Västerås, Västerås, Sweden
[2]. Major LARS is reported in 18 to $56 \%$ and the symptoms appear directly after surgery or after closure of a diverting stoma [3]. Symptoms may improve with time but about 12 to 18 months postoperatively the symptoms reach a plateau and further improvements are unlikely $[4,5]$. In a recent multicenter study, exploring quality of life in patients with LARS, it was determined that quality of life was impaired in patients with major LARS even up to 16 years after surgery [6].

The cause of LARS is multifactorial and may be due to damage to the anal sphincter [7, 8], neural damage during pelvic dissection [7, 8], and altered colonic and neorectal motility [9]. Other identified risk factors for developing LARS are anastomotic height, anastomotic type, total mesorectal excision (TME) versus partial mesorectal excision (PME), adjuvant and neoadjuvant radiotherapy, complications such as anastomotic leakage, and diverting ileostomy $[1,3,10-13]$. 
Yet another factor which could be associated with LARS is the level of transection of the colon that is anastomosed to the anorectal stump. The sigmoid colon could be more rigid with a narrower lumen and with more diverticula compared to the descending colon, which might result in different functional outcomes. To our knowledge, it is not known if the functional outcome is affected whether the sigmoid or descending colon is anastomosed to the anorectum when performing low anterior resection. The primary aim was to explore if rectal cancer patients operated with AR will have poorer bowel function when the sigmoid colon is used for anastomoses compared with the descending colon. Secondarily, we aimed to identify other possible risk factors for bowel dysfunction after AR.

\section{Methods}

This study was based on retrospective analysis of prospectively collected data from a regional population-based registry on all operated patients with rectal cancer diagnosed between January 1996 and January 2019 in the Västmanland County. The data set includes details on pre-, peri-, and postoperative data. Patients were followed up with clinical examinations at $1,6,12,24,36,48$, and 60 months after surgery and the bowel function was registered prospectively (defecatory frequency, urgency, incontinence for flatus and stool, pad usage, clustering/fragmentation, and evacuatory dysfunction) by a colorectal surgeon or a trained nurse specialist using a questionnaire (see Supplementary) [14]. The data from the questionnaire was then registered in the database by a research nurse. The questionnaire of bowel function was set up in 1996 and before the development of the LARS score and did not include any quality of life questions.

A rectal adenocarcinoma was defined as a tumor with its distal margin within $15 \mathrm{~cm}$ from the anal verge measured with a rigid rectoscope. Preoperative screening for metastases was routinely performed. Up until 2002, chest radiography and liver ultrasonography were used, and thereafter, computed tomography of the thorax and abdomen. Magnetic resonance imaging of the rectum was used routinely from 1996 [15]. Stage was defined according to the 6th American Joint Committee on Cancer (AJCC) TNM classification.

\section{Study population}

During the study period, 1062 patients were diagnosed with rectal cancer, whereof 524 underwent AR. In total, 470 patients were stage I-III, after exclusion of primary metastasized rectal cancer $(N=54)$. Data on bowel function were available in 412 patients as 21 patients died before follow-up, one refused follow-up, one had an anastomosis between the ascending colon and rectum, and in 35 patients the diverting stoma became permanent (Fig. 1).

In Table 1, data on the whole cohort with stage I-III rectal cancer who underwent AR is presented $(N=470)$.
Fig. 1 Flowchart of the selection process of rectal cancer patients undergoing anterior resection in the county of Vastmanland, Sweden, 1996-2019
Rectal cancer patients 1062

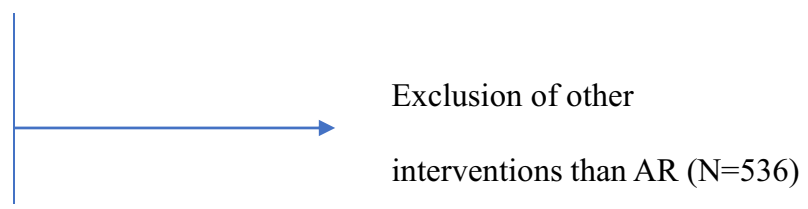

524 patients underwent $\mathrm{AR}$

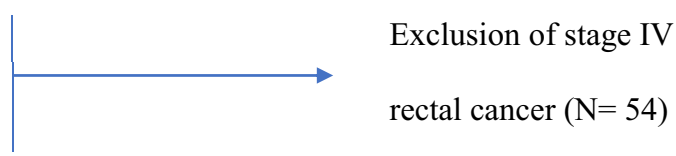

470 patients Stage I-III rectal cancer underwent AR

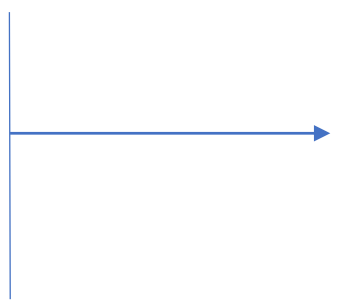

Died before follow up $(\mathrm{N}=21)$

Did not want any follow up $(\mathrm{N}=1)$

Permanent diverting ileostomy $(\mathrm{N}=35)$

Ascending colon in anastomosis $(\mathrm{N}=1)$

412 patients included with

data on functional outcome 
Table 1 Demographics, patient, and surgical characteristics of stage I-III rectal cancer patients undergoing anterior resection for rectal cancer $(N=470)$ after exclusion of primary metastasized rectal cancer

\begin{tabular}{|c|c|}
\hline Variables & Total patients $N=470$ \\
\hline Age $(\text { year })^{\#}$ & $68(32-86)$ \\
\hline Gender (male:female) (\%) & 279:191 (60:40) \\
\hline BMI (kg/m [2] $)^{\#}$ & $26(16-43)$ \\
\hline $\begin{array}{l}\text { ASA } \\
1-2 \\
3 \\
4\end{array}$ & $\begin{array}{l}365(78) \\
105(22) \\
0(0)\end{array}$ \\
\hline $\begin{array}{l}\text { Tumor distance from the anal verge } \\
\text { Low }(3-5 \mathrm{~cm}) \\
\text { Middle }(6-10 \mathrm{~cm}) \\
\text { High }(11-15 \mathrm{~cm})\end{array}$ & $\begin{array}{l}51(11) \\
230(49) \\
189(40)\end{array}$ \\
\hline $\begin{array}{l}\text { Radiotherapy* } \\
\text { Yes } \\
\text { No }\end{array}$ & $\begin{array}{l}320(68) \\
150(32)\end{array}$ \\
\hline $\begin{array}{l}\text { Minimal invasive surgery } \\
\text { Yes } \\
\text { No }\end{array}$ & $\begin{array}{l}37(8) \\
433(92)\end{array}$ \\
\hline $\begin{array}{l}\text { Resection of other organs } \\
\text { Yes } \\
\text { No }\end{array}$ & $\begin{array}{l}75(16) \\
395(84)\end{array}$ \\
\hline $\begin{array}{l}\text { Central ligature IMA } \\
\text { Yes } \\
\text { No } \\
\text { Missing }\end{array}$ & $\begin{array}{l}419(89) \\
49(10) \\
2(1)\end{array}$ \\
\hline $\begin{array}{l}\text { Mobilization of the splenic flexure } \\
\text { Yes } \\
\text { No }\end{array}$ & $\begin{array}{l}407(87) \\
63(13)\end{array}$ \\
\hline $\begin{array}{l}\text { Type of anastomosis } \\
\text { Colonic reservoir } \\
\text { End-to-side colo-anal } \\
\text { End-to-side colo-rectal }\end{array}$ & $\begin{array}{l}77(16) \\
330(70) \\
63(14)\end{array}$ \\
\hline $\begin{array}{l}\text { Part of the colon used for anastomosis } \\
\text { Sigmoid } \\
\text { Descending } \\
\text { Transverse } \\
\text { Ascending }\end{array}$ & $\begin{array}{l}139(29) \\
319(68) \\
11(2) \\
1(1)\end{array}$ \\
\hline Anastomotic level $(\mathrm{cm})^{\#}$ & $4.5(2-11)$ \\
\hline $\begin{array}{l}\text { Type of surgery } \\
\text { TME } \\
\text { PME }\end{array}$ & $\begin{array}{l}422(90) \\
48(10)\end{array}$ \\
\hline $\begin{array}{l}\text { Diverting ileostomy } \\
\text { Yes } \\
\text { No }\end{array}$ & $\begin{array}{l}352(75) \\
118(25)\end{array}$ \\
\hline $\begin{array}{l}\text { T-stage } \\
0-2 \\
3-4\end{array}$ & $\begin{array}{l}200(43) \\
270(57)\end{array}$ \\
\hline $\begin{array}{l}\text { N-stage } \\
0-x \\
1-2\end{array}$ & $\begin{array}{l}293(62) \\
177(38)\end{array}$ \\
\hline $\begin{array}{l}\text { Anastomotic leakage } \\
\text { Yes } \\
\text { No }\end{array}$ & $\begin{array}{l}33(7) \\
437(93)\end{array}$ \\
\hline $\begin{array}{l}\text { Re-laparotomy } \\
\text { Yes } \\
\text { No }\end{array}$ & $\begin{array}{l}15(3) \\
454(97)\end{array}$ \\
\hline
\end{tabular}

Table 1 (continued)

\begin{tabular}{ll}
\hline Variables & Total patients $N=470$ \\
\hline Adjuvant chemotherapy & $186(40)$ \\
Yes & $269(57)$ \\
No & $15(3)$ \\
Missing & \\
\hline
\end{tabular}

$A S A$, American Society of Anesthesiologists; $B M I$, body mass index; $I M A$, inferior mesenteric artery; $T M E$, total mesorectal excision; $P M E$, partial mesorectal excision

*Continuous values are presented as median (range)

Other values in number of patients and parentheses are percentages

**Radiotherapy is any radiotherapy given at any time prior to surgery for rectal cancer, including radiotherapy for cancers other than rectal cancer. Four patients had radiation due to other previous cancer

Tables 2, 3, and 4 present data on functional outcomes in the 412 patients that constituted the study group.

\section{Surgery}

Anterior resection was standardized with either partial mesorectal excision (PME) in tumors in the upper rectum or total mesorectal excision (TME) in middle or low rectal tumors and only performed in the hands of a few colorectal surgeons. Tumors located less than $3-4 \mathrm{~cm}$ from the anal verge did not have an anastomosis due to our local policy, in fear of poor functional results. Central ligation of the inferior mesenteric artery (IMA) 1-2 cm from the aorta or ligation at the superior rectal artery (SRA) close to the origin of the left colic artery (LCA) was performed routinely [16]. Sigmoid, descending, or transverse colon was used for an anastomosis. Which part used depended on the length of the colon, the arterial circulation, the quality of the bowel wall, and the presence of multiple diverticula. The part of the colon having an $\mathrm{S}$ shape is defined as the sigmoid colon and the straight part of the left colon was defined as the descending colon. Between the years 1996 and 2002, only a colonic pouch was used for anastomosis, and thereafter only an end-to-side anastomosis was performed as the standard

Table 2 Major complications after anterior resection and complications leading to re-laparotomy

\begin{tabular}{lll}
\hline Complications & $N=43$ & $\begin{array}{l}\text { Re-laparotomy } \\
(N=15)\end{array}$ \\
\hline Anastomotic leakage & $33(7)$ & 13 \\
Small bowel obstruction & $4(1)$ & 1 \\
Stomal complication & $5(1)$ & 1 \\
Urinary bladder tamponade & $1(0.2)$ & \\
\hline
\end{tabular}

Values in parentheses are percentages 
Table 3 Overview of functional outcome in 412 patients, stage I-III, after anterior resection

\begin{tabular}{ll}
\hline Incontinence & $123(29)$ \\
Yes & $283(69)$ \\
No & $6(2)$ \\
Missing & \\
\hline Evacuatory dysfunction & $65(16)$ \\
Yes & $336(81)$ \\
No & $11(3)$ \\
Missing & \\
Clustering & $234(57)$ \\
Yes & $154(37)$ \\
No & $24(6)$ \\
Missing & \\
Urgency & $91(22)$ \\
Yes & $310(75)$ \\
No & $11(3)$ \\
Missing & \\
\hline
\end{tabular}

Values in number of patients and parentheses are percentages

anastomotic type after LAR. For PME, only end-to-side colorectal anastomosis was used. No straight anastomosis was constructed. The part of the colon used and all other perioperative data were prospectively registered by the surgeons at the time of surgery. Laparoscopic rectal cancer surgery was introduced in the year 2014 and robotic surgery in the year 2016.

\section{Data variables}

Patients were preoperatively asked about defecation habits before symptoms and diagnosis of rectal cancer. Functional outcomes after rectal cancer surgery were registered as dichotomous variables at each follow-up. Incontinence was defined as leakage more than once a week, urgency as a sudden need of defecation, evacuatory dysfunction as defecation lasting more than $15 \mathrm{~min}$ with or without an enema, and clustering/fragmentation as the need of going to the lavatory within $30 \mathrm{~min}$ after defecation (see Supplementary). The functional data after a minimum of 12 months after primary surgery for rectal cancer was used, as evidence has shown that bowel dysfunction becomes more stable 12 months after anterior resection [17, 18]. For patients who received a diverting loop-ileostomy at the primary surgery or within the

Table 4 Univariable logistic regression analysis of functional outcome and risk factors in patients undergoing anterior resection for rectal cancer in Västmanland County $(N=412)$

\begin{tabular}{|c|c|c|c|c|c|c|c|c|c|c|c|c|}
\hline & \multicolumn{3}{|c|}{$\begin{array}{l}\text { Incontinence } \\
(N=406)\end{array}$} & \multicolumn{3}{|c|}{$\begin{array}{l}\text { Urgency } \\
(N=401)\end{array}$} & \multicolumn{3}{|c|}{$\begin{array}{l}\text { Evacuatory } \\
\text { dysfunction } \\
(N=401)\end{array}$} & \multicolumn{3}{|c|}{$\begin{array}{l}\text { Clustering } \\
(N=388)\end{array}$} \\
\hline & OR & $95 \% \mathrm{CI}$ & $P$ & OR & $95 \% \mathrm{CI}$ & $P$ & OR & $95 \% \mathrm{CI}$ & $P$ & OR & $95 \% \mathrm{CI}$ & $P$ \\
\hline Age & 1.03 & $1.00-1.05$ & 0.02 & 0.99 & $0.96-1.01$ & 0.31 & 0.99 & $0.96-1.02$ & 0.50 & 0.97 & $0.95-0.99$ & 0.01 \\
\hline $\begin{array}{l}\text { Gender } \\
\text { Kvinna } \\
\text { Man }\end{array}$ & $\begin{array}{c}1 \\
1.12\end{array}$ & $0.73-1.73$ & 0.60 & $\begin{array}{c}1 \\
1.26\end{array}$ & $0.78-2.05$ & 0.35 & $\begin{array}{c}1 \\
0.92\end{array}$ & $0.54-1.58$ & 0.77 & $\begin{array}{c}1 \\
0.93\end{array}$ & $0.61-1.40$ & 0.71 \\
\hline BMI & 0.96 & $0.91-1.01$ & 0.13 & 1.06 & $1.00-1.12$ & 0.048 & 0.98 & $0.92-1.05$ & 0.65 & 1.03 & $0.98-1.08$ & 0.30 \\
\hline $\begin{array}{l}\text { Radiotherapy* } \\
\text { No } \\
\text { Yes }\end{array}$ & $\begin{array}{c}1 \\
1.69\end{array}$ & $1.03-2.69$ & 0.04 & $\begin{array}{c}1 \\
1.61\end{array}$ & $0.94-2.74$ & 0.08 & $\begin{array}{c}1 \\
1.85\end{array}$ & $0.98-3.48$ & 0.06 & $\begin{array}{c}1 \\
2.10\end{array}$ & $1.36-3.25$ & $<0.001$ \\
\hline $\begin{array}{l}\text { Central ligature IMA } \\
\text { No } \\
\text { Yes }\end{array}$ & $\begin{array}{c}1 \\
1.25\end{array}$ & $0.61-2.60$ & 0.55 & $\begin{array}{c}1 \\
2.28\end{array}$ & $0.87-5.98$ & 0.10 & $\begin{array}{c}1 \\
1.90\end{array}$ & $0.65-5.53$ & 0.24 & $\begin{array}{c}1 \\
1.30\end{array}$ & $0.68-2.45$ & 0.43 \\
\hline Anastomotic level & 0.71 & $0.60-0.83$ & $<0.001$ & 0.92 & $0.80-1.06$ & 0.24 & 0.86 & $0.72-1.02$ & 0.08 & 0.75 & $0.66-0.85$ & $<0.001$ \\
\hline $\begin{array}{l}\text { Part of the colon used for } \\
\text { anastomosis } \\
\text { Descending } \\
\text { Sigmoid }\end{array}$ & $\begin{array}{c}1 \\
0.99\end{array}$ & $0.62-1.56$ & 0.95 & $\begin{array}{c}1 \\
0.58\end{array}$ & $0.34-1.01$ & 0.05 & $\begin{array}{c}1 \\
0.71\end{array}$ & $0.39-1.30$ & 0.27 & $\begin{array}{c}1 \\
1.17\end{array}$ & $0.75-1.81$ & 0.50 \\
\hline $\begin{array}{l}\text { Diverting ileostomy } \\
\text { No } \\
\text { Yes }\end{array}$ & $\begin{array}{c}1 \\
3.12\end{array}$ & $1.74-5.58$ & $<0.001$ & $\begin{array}{c}1 \\
4.09\end{array}$ & $1.97-8.47$ & $<0.001$ & $\begin{array}{c}1 \\
1.69\end{array}$ & $0.86-3.30$ & 0.13 & $\begin{array}{c}1 \\
2.62\end{array}$ & $1.63-4.20$ & $<0.001$ \\
\hline $\begin{array}{l}\text { Adjuvant chemotherapy } \\
\text { No } \\
\text { Yes }\end{array}$ & $\begin{array}{c}1 \\
0.61\end{array}$ & $0.39-0.95$ & 0.03 & $\begin{array}{c}1 \\
1.31\end{array}$ & $0.82-2.10$ & 0.26 & $\begin{array}{c}1 \\
0.81\end{array}$ & $0.47-1.40$ & 0.44 & $\begin{array}{c}1 \\
1.59\end{array}$ & $1.04-2.42$ & 0.03 \\
\hline $\begin{array}{l}\text { Anastomotic leakage } \\
\text { No } \\
\text { Yes }\end{array}$ & $\begin{array}{c}1 \\
2.40\end{array}$ & $0.93-6.21$ & 0.07 & $\begin{array}{c}1 \\
2.50\end{array}$ & $0.92-6.77$ & 0.07 & $\begin{array}{c}1 \\
2.07\end{array}$ & $0.71-6.02$ & 0.18 & $\begin{array}{c}1 \\
2.21\end{array}$ & $0.71-6.90$ & 0.17 \\
\hline
\end{tabular}

$C I$, confidence interval; $O R$, odds ratio 
first 30 days postoperatively due to complications, functional data was registered 12 months after closure of the diverting stoma. Evacuatory dysfunction was added to the follow-up form at a later stage when some patients had missing values.

To avoid sparse variable strata, the ASA scores were recoded into dichotomous variables (ASA 1-2 versus ASA 3-4). The T-stage (T0-2 versus $\mathrm{T} 3$ versus $\mathrm{T} 4$ ) and $\mathrm{N}$-stage (N0 versus $\mathrm{N} 1-\mathrm{N} 2$ ) scores were combined in a similar manner.

Both laparoscopic surgery and robotic surgery were registered as minimal invasive surgery.

In the analysis of the type of colon anastomosed, the remaining part of the descending and the left part of the transverse colon used in anastomosis were merged as one group.

Anastomotic leakage was defined as any clinical signs of leakage, confirmed by radiological examination or endoscopic and clinical examination of the anastomosis. Colovaginal fistula and pelvic abscess were registered as anastomotic leakage.

\section{Statistical analysis}

Continuous data were reported as mean \pm standard deviation (SD) or median with range. Categorical data were analyzed for differences in proportions using the $\chi$ [2] test or Fisher's exact test for low numbers. Univariable and multivariable analyses for factors affecting functional data were performed using logistic regression with goodness of fit evaluated using the Hosmer-Lemeshow test. Collinearity of independent variables in the logistic regression was investigated using the variance inflation factor. Data were analyzed using SPSS software (v. 26; IBM Corp., Armonk, NY, USA).

\section{Ethics}

The study was approved by the Regional Ethics Review Board in Uppsala and complied with the Declaration of Helsinki (Dnr 2014/389 and 2020-05,140).

\section{Results}

The characteristics of all 470 patients with stage I-III who underwent anterior resection with PME or TME for rectal cancer are summarized in Table 1 . The mean age was $67 \pm 9$ years. Sixty percent were male, and the majority were ASA $1-2$. Sixty-eight percent $(n=320)$ received preoperative radiotherapy (RT) of which four had previous radiation due to prostatic or gynecological cancer prior to the rectal cancer diagnosis. Short preoperative RT $(5 \times 5 \mathrm{~Gy})$ was given to $57 \%(N=268)$ and $10 \%(N=48)$ had long preoperative RT (1.8-2×25 Gy). Most anterior resections were performed with open surgery, of which $90 \%$ $(n=422)$ constituted TME. The descending colon was used in 68\% $(N=319)$ when creating the anastomosis and an end-to-side colo-anal anastomosis was performed in $70 \%$ $(N=330)$. Seventy-five percent $(N=352)$ received a diverting ileostomy. Postoperative major surgical complications within 30 days were seen in $9 \%(N=43)$, of which $35 \%$ $(N=15)$ underwent re-laparotomy due to the complications (Table 2). Mortality within 30 days was $0.4 \%(N=2)$ and 90-day mortality was $1 \%(N=6)$.

\section{Functional outcome}

When patients preoperatively were asked about defecation habits before symptoms and diagnosis of rectal cancer, $68 \%$ of patients $(N=282)$ reported "normal" defecation $(1-2$ per day), $4 \%$ defecated every other day $(N=16), 4 \%(N=16)$ had varying stool consistency, and $8 \%(N=31)$ had loose stool more than 3 per day.

Minimum a year after primary surgery or closure of the diverting ileostomy, the median stool frequency was 3 per day (range 0-11). Perianal skin irritation was observed in $10 \%(N=42)$. Due to change in bowel habits, $10 \%(N=40)$ used motility-promoting medications, $29 \%(N=121)$ used inhibitory medications, and $7 \%(N=27)$ used a combination of these. Pad usage was registered in $39 \%(N=162)$. The most common functional defecatory outcome is clustering (57\%) and incontinence (29\%) followed by urgency (22\%) and evacuatory dysfunction (16\%) (Table 3).

\section{Risk factors for functional outcome}

With age, the risk of incontinence increased by $3 \%$ and equally reduced for clustering in the univariable analysis (Table 4), but in the multivariable analysis, age was only significantly associated with clustering (Table 5). Gender showed limited association with functional difficulties in the current study. The anastomotic level had significant association with defecatory outcome. The higher anastomoses, in relation to the anal verge, the lower the risk in both the univariable and multivariable analyses of both incontinence (OR 0.75; CI 0.63-0.90; $p<0.001$ ) and clustering (OR 0.78; CI $0.67-0.90 ; p<0.001$ ) (Tables 4 and 5 ). The part of the colon, sigmoid or descendening, that was used for anastomosis was not significantly associated with any functional outcome (Tables 4 and 5). Neither was there an association seen on defecatory function regarding level of vascular ligature (Tables 4 and 5).

In median, the time from stoma creation to closure was 8 months (range 1-29 months). After closure of the diverting ileostomy, there was a significant increased risk of clustering (OR 1.89; 1.08-3.31; $p=0.03$ ), incontinence (OR 2.48; 
Table 5 Multivariabel logistic regression analysis of functional outcome and risk factors in patients undergoing anterior resection for rectal cancer in Västmanland County $(\mathrm{N}=412)$

\begin{tabular}{|c|c|c|c|c|c|c|c|c|c|c|c|c|}
\hline & \multicolumn{3}{|c|}{$\begin{array}{l}\text { Incontinence } \\
(N=406)\end{array}$} & \multicolumn{3}{|c|}{$\begin{array}{l}\text { Urgency } \\
(N=401)\end{array}$} & \multicolumn{3}{|c|}{$\begin{array}{l}\text { Evacuatory } \\
\text { dysfunction } \\
(N=401)\end{array}$} & \multicolumn{3}{|c|}{$\begin{array}{l}\text { Clustering } \\
(N=388)\end{array}$} \\
\hline & OR & $95 \% \mathrm{CI}$ & $P$ & OR & $95 \% \mathrm{CI}$ & $P$ & OR & 95\% CI & $\boldsymbol{P}$ & OR & 95\% CI & $P$ \\
\hline Age & 1.02 & $1.00-1.05$ & 0.09 & 0.99 & $0.96-1.02$ & 0.38 & 0.99 & $0.96-1.02$ & 0.38 & 0.97 & 0.95-1.00 & 0.02 \\
\hline $\begin{array}{l}\text { Gender } \\
\text { Kvinna } \\
\text { Man }\end{array}$ & $\begin{array}{c}1 \\
1.06\end{array}$ & $0.66-1.70$ & 0.82 & $\begin{array}{c}1 \\
1.10\end{array}$ & $0.65-1.85$ & 0.73 & $\begin{array}{c}1 \\
0.86\end{array}$ & $0.49-1.53$ & 0.61 & $\begin{array}{c}1 \\
0.86\end{array}$ & $0.54-1.37$ & 0.52 \\
\hline BMI & 0.97 & $0.92-1.04$ & 0.40 & 1.05 & $0.99-1.12$ & 0.13 & 0.99 & $0.92-1.06$ & 0.76 & 1.03 & $0.97-1.09$ & 0.40 \\
\hline $\begin{array}{l}\text { Radiotherapy* } \\
\text { No } \\
\text { Yes }\end{array}$ & $\begin{array}{c}1 \\
1.16\end{array}$ & $0.67-2.00$ & 0.60 & $\begin{array}{c}1 \\
1.14\end{array}$ & $0.62-2.08$ & 0.68 & $\begin{array}{c}1 \\
1.52\end{array}$ & $0.77-3.03$ & 0.23 & $\begin{array}{c}1 \\
1.45\end{array}$ & $0.87-2.40$ & 0.15 \\
\hline $\begin{array}{l}\text { Central ligature IMA } \\
\text { No } \\
\text { Yes }\end{array}$ & $\begin{array}{c}1 \\
1.37\end{array}$ & $0.58-3.21$ & 0.47 & $\begin{array}{c}1 \\
2.02\end{array}$ & $0.69-5.90$ & 0.20 & $\begin{array}{c}1 \\
1.43\end{array}$ & $0.44-4.65$ & 0.55 & $\begin{array}{c}1 \\
1.56\end{array}$ & $0.70-3.48$ & 0.28 \\
\hline Anastomotic level & 0.75 & $0.63-0.90$ & $<0.001$ & 1.02 & $0.86-1.22$ & 0.81 & 0.94 & $0.78-1.14$ & 0.54 & 0.78 & $0.67-0.90$ & $<0.001$ \\
\hline $\begin{array}{l}\text { Part of the colon used for } \\
\text { anastomosis } \\
\text { Descending } \\
\text { Sigmoid }\end{array}$ & $\begin{array}{c}1 \\
1.18\end{array}$ & $0.68-2.05$ & 0.57 & $\begin{array}{c}1 \\
0.67\end{array}$ & $0.36-1.25$ & 0.21 & $\begin{array}{c}1 \\
0.78\end{array}$ & $0.39-1.56$ & 0.49 & $\begin{array}{c}1 \\
1.71\end{array}$ & $0.98-2.98$ & 0.06 \\
\hline $\begin{array}{l}\text { Diverting ileostomy } \\
\text { No } \\
\text { Yes }\end{array}$ & $\begin{array}{c}1 \\
2.48\end{array}$ & $1.29-4.77$ & 0.01 & $\begin{array}{c}1 \\
4.61\end{array}$ & $2.02-10.6$ & $<0.001$ & $\begin{array}{c}1 \\
1.45\end{array}$ & $0.69-3.03$ & 0.33 & $\begin{array}{c}1 \\
1.89\end{array}$ & $1.08-3.31$ & 0.03 \\
\hline $\begin{array}{l}\text { Adjuvant chemotherapy } \\
\text { No } \\
\text { Yes }\end{array}$ & $\begin{array}{c}1 \\
0.74\end{array}$ & $0.46-1.20$ & 0.22 & $\begin{array}{c}1 \\
1.20\end{array}$ & $0.72-2.01$ & 0.49 & $\begin{array}{c}1 \\
0.77\end{array}$ & $0.43-1.37$ & 0.37 & $\begin{array}{c}1 \\
1.51\end{array}$ & $0.94-2.40$ & 0.09 \\
\hline $\begin{array}{l}\text { Anastomotic leakage } \\
\text { No } \\
\text { Yes }\end{array}$ & $\begin{array}{c}1 \\
1.75\end{array}$ & $0.66-4.66$ & 0.26 & $\begin{array}{c}1 \\
2.07\end{array}$ & $0.74-5.81$ & 0.17 & $\begin{array}{c}1 \\
1.75\end{array}$ & $0.59-5.24$ & 0.32 & $\begin{array}{c}1 \\
1.93\end{array}$ & $0.59-6.29$ & 0.28 \\
\hline
\end{tabular}

$C I$, confidence interval; $O R$, odds ratio

$1.29-4.77 ; p<0.01$ ), and urgency (OR 4.61; CI 2.02-10.60; $p<0.001$ ) in the multivariable analysis (Tables 4 and 5). Anastomotic leakage was not associated with any functional difficulties in neither the univariable nor the multivariable analysis (Tables 4 and 5). Radiotherapy given prior to surgery and postoperative adjuvant chemotherapy was not significant in the multivariable analysis (Table 5).

Goodness-of-fit tests for all logistic regression models used for risk factor analyses were all non-significant, indicating satisfactory fit of all models.

\section{Discussion}

Anterior resection for rectal cancer is closely linked with functional outcome in patients. The part of the colon used for anastomosis-descending or sigmoid colon-was not a significantly associated functional outcome after anterior resection in this study. However, low anastomotic level was associated with incontinence and clustering. Anastomotic leakage was not observed to covary with intestinal function but receiving a diverting ileostomy increased the risk of having functional difficulties 1 year after closure. Gender and pre- or postoperative oncological treatment were not associated with intestinal function but the risk for clustering decreased with increasing age.

The primary aim was to examine if sigmoid or descending colon used in anastomosis led to worse functional outcome. The sigmoid compared with the descending colon could be more rigid with a narrower lumen and may have multiple diverticula, which might hypothetically result in defecatory dysfunction. We did not find level of intestinal transection to be significantly associated with functional outcome. However, the sigmoid colon was only used for anastomoses when it was assessed during surgery to have a normal bowel thickness without multiple diverticula and the transection line was always governed by the arterial circulation at the distal bowel end.

When performing low anterior resection, the vascular ligation is either centrally at the IMA close to the aorta or peripheral at the superior rectal artery at varying levels. There is no consensus where the preferred vascular ligation 
should be regarding functional outcome postoperatively. Central ligation may cause sympathetic nerve damage causing fecal incontinence as well as urinary and sexual disturbances [19]. In a study on the Swedish national registry, no difference was found between central or peripheral ligature on the risk of defecatory disturbances 2 years after anterior resection [20]. There are two randomized trials with discrepant results: one which did not find any difference in risk for defecatory disturbances regardless of level of ligation [21] and the other which found increased stool frequency after central ligation [22]. We did not find an association between functional outcome and level of vascular ligation in this study, probably because at our department the mean difference between a central ligation and the peripheral ligation, which is done close to the origin of the left colic artery, was less than $1 \mathrm{~cm} \mathrm{[16].}$

Low anastomotic level increased the risk of incontinence and clustering. This is in accordance with some studies, where low anastomotic height was associated with major low anterior resection syndrome (LARS) [2, 18, 23-26]. It has been suggested that functional outcome after rectal resection is due to reduced neorectal compliance when constructing a low anastomosis [9, 24, 27]. Thus, probably, it is important to preserve as much rectum as possible to reduce risk of functional difficulties after surgery.

Today, it is standard practice to use a diverting ileostomy following low anterior resection, to reduce the consequences of an anastomotic leak [28]. However, fashioning a diverting ileostomy has been shown to have negative consequences on the bowel function in several studies [12, $27,29,30]$. Our results show an increased risk of incontinence, urgency, and clustering after 12 months of diverting ileostomy closure. There are emerging studies indicating timing of stoma closure to be important for bowel function with cutoffs at approximately 3 months [18, 30, 31] or 6 months [1]. The median time to closure in this study was 8 months, maybe explaining the association to bowel dysfunction.

In a recent meta-analysis of LARS and risk factors, having anastomotic leakage was found, in several studies, to be associated with increased risk of major LARS (3). However, some studies have not shown increased risk following anastomotic leakage $[1,18,24]$, in accordance with our findings. The possible discrepancy in the results is due to different definitions of anastomotic leakage and size of cohorts. In this cohort, a type II error may explain why anastomotic leakage was not associated with significant increase risk of incontinence in the multivariable analysis.

Preoperative RT has consistently been shown to be a risk factor for LARS in studies, both after short and especially long courses [1, 2, 18, 23-26]. In our study, the majority had short-course preoperative RT with a negative impact on continence and clustering in the univariable analysis, but not in the multivariable analysis when adjusted for anastomotic level. This is in accordance with a recent Scandinavian study where radiotherapy as a risk factor for LARS was abolished when adjusted for tumor height [32]. Another possible explanation for the lack of association between RT and bowel function could be due to the number of variables used in the multivariable analysis, reducing power in the analysis.

The main strengths of this study are that the data were registered prospectively, which limits the bias associated with retrospectively collected data. The data are based on a large population-based homogenous cohort and included all patients with rectal cancer operated with anterior resection, in the county since 1996. Furthermore, there could be benefits of a single-center study, such as surgery being standardized and performed by a few experienced colorectal surgeons, with the same approach to treatment of rectal cancer patients, consensus on the definitions of all variables, as well as all variables being registered at each follow-up visit in a protocol by the same nurse and surgeons.

The main limitation of this study concerning choice of colon segment for anastomosis could be its non-randomized design and the lack of exact distance of the transection level of the sigmoid or descending colon to the anal verge. However, as for practical reasons, a randomization would be difficult as several technical factors are involved such as status of bowel segment and arterial circulation. Furthermore, the data were not based on the validated LARS score not fully comparable to studies on LARS; however, the functional outcome variables selected cover almost the same symptoms as in the LARS score. The questions in the questionnaire were asked by the treating surgeons and nurse, maybe introducing response bias and affect the validity of the questions; however, the same method was used for all patients why the results should still be valid. Finally, for the variable evacuatory dysfunction, conclusions from this variable should be made cautiously due to low statistical precision and subsequent confidence interval width.

\section{Conclusion}

The part of the colon used for anastomosis-descending or sigmoid colon-was not a significantly associated functional outcome after anterior resection when the quality of the bowel wall and adequate distal arterial blood circulation are taken into consideration in the present study, although further studies are needed to settle this question. Low anastomotic level is associated with incontinence and clustering and having had a diverting ileostomy is also associated with functional difficulties after stoma reversal. Patients should be given this information when confirming their consent for low anterior resection. 
Supplementary Information The online version contains supplementary material available at https://doi.org/10.1007/s00384-021-04024-3.

Funding Open access funding provided by Uppsala University.

\section{Declarations}

Conflict of interest The authors declare no competing interests.

Open Access This article is licensed under a Creative Commons Attribution 4.0 International License, which permits use, sharing, adaptation, distribution and reproduction in any medium or format, as long as you give appropriate credit to the original author(s) and the source, provide a link to the Creative Commons licence, and indicate if changes were made. The images or other third party material in this article are included in the article's Creative Commons licence, unless indicated otherwise in a credit line to the material. If material is not included in the article's Creative Commons licence and your intended use is not permitted by statutory regulation or exceeds the permitted use, you will need to obtain permission directly from the copyright holder. To view a copy of this licence, visit http://creativecommons.org/licenses/by/4.0/.

\section{References}

1. Hughes DL, Cornish J, Morris C (2017) Functional outcome following rectal surgery-predisposing factors for low anterior resection syndrome. Int J Colorectal Dis 32(5):691-697

2. Emmertsen KJ, Laurberg S (2012) Low anterior resection syndrome score: development and validation of a symptom-based scoring system for bowel dysfunction after low anterior resection for rectal cancer. Ann Surg 255(5):922-928

3. Croese AD, Lonie JM, Trollope AF, Vangaveti VN, Ho YH (2018) A meta-analysis of the prevalence of low anterior resection syndrome and systematic review of risk factors. International journal of surgery (London, England) 56:234-241

4. Emmertsen KJ, Laurberg S (2013) Impact of bowel dysfunction on quality of life after sphincter-preserving resection for rectal cancer. Br J Surg 100(10):1377-1387

5. Ho YH (2006) Techniques for restoring bowel continuity and function after rectal cancer surgery. World J Gastroenterol 12(39):6252-6260

6. Pieniowski EHA, Palmer GJ, Juul T et al (2019) Low anterior resection syndrome and quality of life after sphincter-sparing rectal cancer surgery: a long-term longitudinal follow-up. Dis Colon Rectum 62(1):14-20

7. Bryant CL, Lunniss PJ, Knowles CH, Thaha MA, Chan CL (2012) Anterior resection syndrome. Lancet Oncol 13(9):e403-408

8. Dulskas A, Miliauskas P, Tikuisis R, Escalante R, Samalavicius NE (2016) The functional results of radical rectal cancer surgery: review of the literature. Acta Chir Belg 116(1):1-10

9. Emmertsen KJ, Bregendahl S, Fassov J, Krogh K, Laurberg S (2013) A hyperactive postprandial response in the neorectumthe clue to low anterior resection syndrome after total mesorectal excision surgery? Colorectal disease : the official journal of the Association of Coloproctology of Great Britain and Ireland 15(10):e599-606

10. Chen TY, Wiltink LM, Nout RA et al (2015) Bowel function 14 years after preoperative short-course radiotherapy and total mesorectal excision for rectal cancer: report of a multicenter randomized trial. Clin Colorectal Cancer 14(2):106-114
11. Gadan S, Floodeen H, Lindgren R, Matthiessen P (2017) Does a defunctioning stoma impair anorectal function after low anterior resection of the rectum for cancer? A 12-year follow-up of a randomized multicenter trial. Dis Colon Rectum 60(8):800-806

12. Jimenez-Gomez LM, Espin-Basany E, Trenti L et al (2017) Factors associated with low anterior resection syndrome after surgical treatment of rectal cancer. Colorectal disease : the official journal of the Association of Coloproctology of Great Britain and Ireland

13. Kupsch J, Jackisch T, Matzel KE et al (2018) Outcome of bowel function following anterior resection for rectal cancer-an analysis using the low anterior resection syndrome (LARS) score. Int J Colorectal Dis 33(6):787-798

14. Strand E, Nygren I, Bergkvist L, Smedh K (2011) Nurse or surgeon follow-up after rectal cancer: a randomized trial. Colorectal disease : the official journal of the Association of Coloproctology of Great Britain and Ireland 13(9):999-1003

15. Videhult P, Smedh K, Lundin P, Kraaz W (2007) Magnetic resonance imaging for preoperative staging of rectal cancer in clinical practice: high accuracy in predicting circumferential margin with clinical benefit. Colorectal disease : the official journal of the Association of Coloproctology of Great Britain and Ireland 9(5):412-419

16. Tiselius C, Kindler C, Rosenblad A, Smedh K (2019) Localization of mesenteric lymph node metastases in relation to the level of arterial ligation in rectal cancer surgery. European journal of surgical oncology : the journal of the European Society of Surgical Oncology and the British Association of Surgical Oncology 45(6):989-994

17. Camilleri-Brennan J, Steele RJ (2001) Prospective analysis of quality of life and survival following mesorectal excision for rectal cancer. Br J Surg 88(12):1617-1622

18. Sturiale A, Martellucci J, Zurli L et al (2017) Long-term functional follow-up after anterior rectal resection for cancer. Int $\mathrm{J}$ Colorectal Dis 32(1):83-88

19. Höer J, Roegels A, Prescher A, Klosterhalfen B, Töns C, Schumpelick V (2017) Preserving autonomic nerves in rectal surgery. Results of surgical preparation on human cadavers with fixed pelvic sections. Der Chirurg; Zeitschrift fur alle Gebiete der operativen Medizen 71(10):1222-1229

20. Kverneng Hultberg D, Afshar AA, Rutegård J et al (2017) Level of vascular tie and its effect on functional outcome 2 years after anterior resection for rectal cancer. Colorectal disease : the official journal of the Association of Coloproctology of Great Britain and Ireland 19(11):987-995

21. Matsuda K, Hotta T, Takifuji K et al (2015) Randomized clinical trial of defaecatory function after anterior resection for rectal cancer with high versus low ligation of the inferior mesenteric artery. Br J Surg 102(5):501-508

22. Wang Q, Zhang C, Zhang H, Wang Y, Yuan Z, Di C (2015) Effect of ligation level of inferior mesenteric artery on postoperative defecation function in patients with rectal cancer. Zhonghua wei chang wai ke za zhi $=$ Chinese $\mathbf{J}$ Gastrointestin Surg 18(11):1132-1135

23. Bondeven P, Emmertsen KJ, Laurberg S, Pedersen BG (2015) Neoadjuvant therapy abolishes the functional benefits of a larger rectal remnant, as measured by magnetic resonance imaging after restorative rectal cancer surgery. European journal of surgical oncology : the journal of the European Society of Surgical Oncology and the British Association of Surgical Oncology 41(11):1493-1499

24. Carrillo A, Enríquez-Navascués JM, Rodríguez A et al (2016) Incidence and characterization of the anterior resection syndrome through the use of the LARS scale (low anterior resection score). Cirugia espanola 94(3):137-143

25. Hain E, Manceau G, Maggiori L, Mongin C, Prost À la Denise J, Panis Y (2017) Bowel dysfunction after anastomotic leakage 
in laparoscopic sphincter-saving operative intervention for rectal cancer: a case-matched study in 46 patients using the Low Anterior Resection Score. Surgery 161(4):1028-1039

26. Juul T, Battersby NJ, Christensen P et al (2015) Validation of the English translation of the low anterior resection syndrome score. Colorectal disease : the official journal of the Association of Coloproctology of Great Britain and Ireland 17(10):908-916

27. Wells CI, Vather R, Chu MJ, Robertson JP, Bissett IP (2015) Anterior resection syndrome-a risk factor analysis. J Gastrointest Surg 19(2):350-359

28. Matthiessen P, Hallbook O, Rutegard J, Simert G, Sjodahl R (2007) Defunctioning stoma reduces symptomatic anastomotic leakage after low anterior resection of the rectum for cancer: a randomized multicenter trial. Ann Surg 246(2):207-214

29. Battersby NJ, Bouliotis G, Emmertsen KJ et al (2018) Development and external validation of a nomogram and online tool to predict bowel dysfunction following restorative rectal cancer resection: the POLARS score. Gut 67(4):688-696
30. Walma MS, Kornmann VN, Boerma D, de Roos MA, van Westreenen HL (2015) Predictors of fecal incontinence and related quality of life after a total mesorectal excision with primary anastomosis for patients with rectal cancer. Annals of coloproctology 31(1):23-28

31. Keane C, Park J, Öberg S et al (2019) Functional outcomes from a randomized trial of early closure of temporary ileostomy after rectal excision for cancer. Br J Surg 106(5):645-652

32. Sandberg S, Asplund D, Bisgaard T et al (2020) Low anterior resection syndrome in a Scandinavian population of patients with rectal cancer: a longitudinal follow-up within the QoLiRECT study. Colorectal disease : the official journal of the Association of Coloproctology of Great Britain and Ireland 22(10):1367-1378

Publisher's Note Springer Nature remains neutral with regard to jurisdictional claims in published maps and institutional affiliations. 